\title{
EXAMEN CRÍTICO DE LA SENTENCIA ANTICIPADA EN EL PROCEDIMIENTO MONITORIO LABORAL
}

\author{
Claudio Palavecino Cáceres* \\ CRISTIÁN PABLO RAMÍrEZ SOTO** \\ Universidad de Chile
}

\begin{abstract}
RESUMEN: En el procedimiento monitorio laboral chileno se faculta al juez para dictar sentencia sin oír al demandado. Se ha querido asimilar esta sentencia anticipada a la intimación judicial de pago de las formas monitorias europeas. Pero, en estas, la resolución que se dicta inaudita altera parte no es todavía sentencia, puesto que la fase de cognición no está completa sino hasta que trascurra el término para que el demandado pueda oponerse. En cambio, en nuestro monitorio, la pasividad del perdidoso no cumple ninguna función en relación con la cognición, puesto que el litigio se decide antes de iniciar siquiera el transcurso del término para la oposición. Con lo cual, el procedimiento monitorio laboral no consigue sortear la objeción que plantea la regla constitucional según la cual "toda sentencia de un órgano que ejerza jurisdicción debe fundarse en un proceso previo legalmente tramitado".
\end{abstract}

Palabras clave: Procedimiento monitorio, sentencia anticipada, debido proceso.

ABSTRACT: In the Chilean monitor procedure the judge is empowered to sentence without hearing the defendant. They wanted to assimilate this anticipated sentence to the judicial plea for payment of the European monitory forms. But in these, the resolution dictated inaudita altera parte it is not yet a sentence, since the stage of congnition is not complete until the term elapses so that the defendant could object. In contrast, in our monitory, the passivity od the loser serves no purpose in relation to the cognition, since the dispute is decided before even starting the course of the term for the opposition. Thus, the monitory procedure fails to circumvent the objection raised by the constitutional rule according to which "any sentence of a court exercising jurisdiction must be based on a previous process legally processed".

Key words: Monitory procedure, anticipated sentence, due process.

\section{INTRODUCCIÓN}

Como reacción a la queja secular contra la lentitud de los juicios se erige hoy la rapidez como un objetivo ineludible de los sistemas procesales. Se persigue "una tutela jurisdiccional rápida, pero sin merma de los derechos de los justiciables"1 $\mathrm{y}$, con miras a conseguirla se impone a los procedimiento jurisdiccionales la sumariedad cuantitativa, entendida como acortamiento de plazos y supresión de requisitos y de trámites ${ }^{2}$. Los reformadores de la jurisdicción laboral

\footnotetext{
- Profesor del Departamento de Derecho del Trabajo y la Seguridad Social, Facultad de Derecho de la Universidad de Chile.

"*Ayudante del Departamento de Derecho del Trabajo y la Seguridad Social, Facultad de Derecho de la Universidad de Chile.

${ }^{1}$ CEDEÑO, M. "El proceso monitorio en el ordenamiento español. Un cauce para la eficaz protección del crédito", en: DE LA Oliva, A. y Palomo, D. (coord.). Proceso civil. Hacia una nueva justicia civil. Santiago: Editorial Jurídica de Chile, 2007, p. 430.

${ }^{2}$ AlBIOL, I.; Alfonso C.; BLAsCo, A.; y GoERLiCH, J. Ma. Derecho Procesal Laboral, -3a edición-. Valencia: Tirant lo Blanch, 2000 , p. 340 .
} 
Claudio Palavecino Cáceres y Cristián Pablo Ramírez Soto / Examen crítico de la sentencia anticipada...

en Chile no han sido ajenos a este afán por imprimir velocidad a los juicios, aunque sin demasiada consideración por aquel sistema de garantías procesales que las naciones más civilizadas conocen como debido o justo proceso. La nueva legislación procesal laboral chilena menciona precisamente entre los principios que primarán en los procedimientos del trabajo a la tan anhelada celeridad -artículo 425 CT-, y es justo reconocer que los reformadores no se quedaron simplemente en la formulación de un buen propósito, sino que lo materializaron al configurar un procedimiento acelerado, al que llamaron monitorio (artículos 496 al 502 CT).

Si bien en el ordenamiento interno el procedimiento monitorio es de introducción reciente $^{3}$-lo cual ha generado comprensible desconcierto en los operadores jurídicos-, las denominadas formas monitorias son conocidas y aplicadas desde antiguo ${ }^{4}$ y extensamente en el Derecho europeo. Estas formas monitorias buscan el mismo resultado que el proceso declarativo ordinario, a saber, la obtención de un título ejecutivo judicial, pero de una forma más simplificada y, por ende, más rápida que aquel. En las formas monitoras, la sumariedad cuantitativa se cumple mediante una intimación judicial de pago a petición del solicitante, requirente o actor que emite el órgano jurisdiccional sin oír al requerido o demandado, vale decir, sin contradictorio 5 . Solo si existe oposición de este se pasará a un proceso contradictorio de conocimiento - eventualidad del contradictorio- ${ }^{6}$. En cambio, la inactividad del requerido o demandado se pagará a un precio muy caro: el inmediato despacho de la ejecución contra él ${ }^{7}$, puesto que su silencio es tomado ya como confesión, ya como allanamiento y/o reconocimiento tácito de la pretensión del solicitante/actor ${ }^{8}$. Como se ve, la finalidad de llegar con celeridad a la creación del título ejecutivo se alcanza desplazando la iniciativa del contradictorio del actor al demandado?.

El monitorio se inscribe dentro de los llamados procedimientos urgentes o tutelas especiales diferenciadas ${ }^{10}$ que se caracterizan por tener incorporados fuertemente en sus distintas figuras los principios de celeridad procesal, economía procesal y postergación o disminución del principio de contradicción. Precisamente, en la restricción al derecho de defensa en juicio del demandado radica el principal objeto de críticas contra estos procedimientos ${ }^{11}$.

\footnotetext{
${ }^{3}$ La reforma procesal penal introdujo ya un procedimiento monitorio (Vid. artículo 392 CPP).

${ }^{4}$ Ya en el año 1926, Calamandrei publicó un estudio sobre el procedimiento monitorio: Il procedimento monitorio nella Legislazione Italiana. Milano: Società Editrice Unitas, 1926.

5 Alvarado Velloso opina que el llamado proceso monitorio, al funcionar solo con uno de los interesados, no es propiamente un proceso, sino un mero procedimiento. Alvarado, A. Sistema Procesal. Garantía de la libertad. Buenos Aires: RubinzalCulzoni, 2009, tomo II, p. 353.

${ }^{6}$ PEREZ, A. "En torno al proceso monitorio desde el derecho procesal comparado europeo y hacia un monitorio comunitario. Caracterización y elementos", en: DE LA OlIVA, A. y PALOMO, D. (coord.). Proceso civil. Hacia una nueva justicia civil. Santiago: Editorial Jurídica de Chile, 2007, pp. 457-459.

${ }^{7}$ CEDEÑO, M., op. cit. (n. 1), p. 432.

${ }^{8}$ PÉREZ, A., op. cit. (n. 6), p. 458.

9 CALAMANDREI, P. El procedimiento monitorio. Buenos Aires: Ediciones Jurídicas Europa-América (EJEA), 1953, p. 25.

10 "Las técnicas de simplificación y sumariedad de la cognición que sustentan la denominada genéricamente tutela anticipatoria y los procesos urgentes en general persiguen asegurar la eficacia en concreto de la prestación jurisdiccional, y al mismo objetivo tienden, entre otras, las estructuras monitorias, la decisión temprana de la litis y la ejecución provisional de la sentencia. Son todos mecanismos simplificadores tendientes a superar las dilaciones del proceso común" (Berizonce, R.: Tutelas procesales diferenciadas, Rubinzal-Culzoni, Buenos Aires, 2009, p. 92.
}

${ }^{11}$ ÁlvareZ, P. Tutela Anticipada. Córdoba -Argentina-: Alveroni Ediciones, 2008, p. 12. 
En efecto, si alguien afirmara que en un procedimiento judicial existe la posibilidad de condenar al demandado sin audiencia previa, lo más probable es que surgieran inmediatamente comprensibles aprensiones sobre la adecuación de tal procedimiento al sistema de garantías del debido proceso. Por de pronto, en nuestro país, respecto de la regla constitucional conforme a la cual toda sentencia de un órgano que ejerza jurisdicción debe fundarse en un proceso previo legalmente tramitado -artículo 19. No 3 CPR-. Sin embargo, las formas monitorias parecen haber sorteado satisfactoriamente el examen relativo a su compatibilidad con el debido proceso. En efecto, doctísimos autores y la jurisprudencia de las altas cortes europeas no han formulado reparos a la estructura invertida y eventualidad del contradictorio y coinciden en que la mera posibilidad de provocarlo mediante la oposición al requerimiento es garantía suficiente para el demandado de su derecho a ser oído ${ }^{12}$. Tales argumentos han sido citados por el iuslaboralismo chileno como concluyentes y definitivos para justificar que el procedimiento monitorio laboral se adecua también al debido proceso ${ }^{13}$.

Si las formas monitorias gozan de larga vida y buena salud en Europa y, encima, han sido avaladas por destacados procesalistas y la jurisprudencia de las cortes ¿qué sentido tiene, entonces, nuestra propuesta de un examen crítico de la sentencia anticipada en procedimiento monitorio? La respuesta es simple: la doctrina iuslaboralista nacional ha obviado -posiblemente de manera interesada- las diferencias sustantivas que existen entre nuestro procedimiento monitorio laboral y las formas monitorias europeas. Siguiendo una lógica harto simplista, se parte de la premisa que si el legislador llamó monitorio al procedimiento acelerado que nos ocupa, entonces, su estructura puede encuadrarse, sin mayor análisis, en esas formas monitorias europeas. Luego, lo que valga para estas últimas valdrá también para nuestro monitorio. Sin embargo, hace rato que en el Derecho del trabajo chileno nomina non sunt consequentia rerum ${ }^{14}$ de modo que si se pretende legitimar al procedimiento monitorio laboral desde un punto de vista garantista con los argumentos a favor de las formas monitorias se impone, como mínima precaución científica, corroborar primero si nuestra modalidad procesal pertenece a tal categoría. Como ya adelantamos, el procedimiento monitorio laboral chileno presenta diferencias sustantivas respecto de las formas monitorias europeas. Veremos que son justamente esas desviaciones respecto de los modelos europeos las que generan un déficit garantístico insalvable al procedimiento monitorio laboral chileno.

\section{EL PROCEDIMIENTO MONITORIO LABORAL CHILENO}

El procedimiento monitorio que creó en Chile la reforma a la jurisdicción laboral tiene varias singularidades que lo hacen único en su género.

En primer lugar, en los distintos ordenamientos jurídicos que regulan el procedimiento monitorio, este no suele configurarse como un cauce general en el que tenga cabida cual-

\footnotetext{
12 PEREZ, A., op. cit. (n. 6), pp. 463-466.

13 PeREIRA, R. El procedimiento monitorio laboral. Santiago: Abeledo Perrot LegalPublishing, 2010, pp. 12-13.

${ }^{14} \mathrm{Y}$ así tenemos en materia laboral una responsabilidad que solo nominalmente es solidaria y una nulidad de despido que tampoco es tal.
} 
quier tipo de reclamaciones de tutela jurisdiccional ${ }^{15}$. La legislación chilena, en cambio, determina el ámbito de aplicación de este procedimiento básicamente en función de la cuantía de la contienda ${ }^{16}$, de manera que prácticamente cualquier controversia que se ajuste a este parámetro puramente cuantitativo podrá ventilarse bajo la modalidad procesal en comento.

Enseguida, este procedimiento, según el texto expreso de la ley, tiene una primera instancia $^{17}$ o etapa administrativa ${ }^{18}$ que consiste en un comparendo de conciliación ante la Inspección del Trabajo ${ }^{19}$. La ley ordena a las partes concurrir al comparendo de conciliación con los instrumentos probatorios de que dispongan -inciso 4 del artículo 497 CT-. La comparecencia del reclamante a la instancia administrativa es obligatoria para la prosecución del procedimiento, puesto que si no se presenta al comparendo estando citado legalmente no podrá luego continuar su reclamo ante el órgano judicial, sino conforme a las reglas del procedimiento de aplicación general -artículo. $498 \mathrm{CT}-{ }^{20}$.

Si la conciliación fracasa o es parcial o el reclamado no concurre al comparendo, el trabajador podrá interponer demanda escrita ante el juez del Trabajo competente, en cuyo caso deberá acompañar el acta levantada en el comparendo por el funcionario fiscalizador y los documentos presentados en este -artículo $499 \mathrm{CT}$-.

\footnotetext{
${ }^{15}$ Cedeño, M., op. cit. (n. 1), p. 432.

${ }^{16} \mathrm{El}$ artículo $496 \mathrm{CT}$ prescribe que el procedimiento monitorio se aplicará "respecto de las contiendas cuya cuantía sea igual o inferior a diez ingresos mínimos mensuales, sin considerar, en su caso, los aumentos a que hubiere lugar por aplicación de los incisos quinto y séptimo del artículo 162; y de las contiendas a que se refiere el artículo $201 . .$. .

${ }^{17} \mathrm{El}$ artículo 498, inciso $1 \mathrm{CT}$, señala que en caso de incomparecencia del reclamante al comparendo "se pondrá término a dicha instancia".

${ }^{18} \mathrm{El}$ artículo 500 inciso $1 \mathrm{CT}$, alude a "la comparecencia de las partes en la etapa administrativa".

19 Se exceptúan de esta exigencia las acciones referentes al fuero maternal -artículo 497 inciso 2 CT-.

20 Esta primera etapa o instancia del procedimiento, desarrollada en sede administrativa, contraviene manifiestamente la proscripción constitucional del ejercicio de funciones jurisdiccionales por parte de la Administración y viola el derecho constitucional al juez natural, esto es, el derecho a que la causa sea conocida y resuelta por un tribunal y no por organismos pseudojurisdiccionales. Si bien la Dirección del Trabajo es un servicio público descentralizado, con personalidad jurídica y patrimonio propios, no es un órgano independiente, puesto que está sometido a la supervigilancia del Presidente de la República a través del Ministerio del Trabajo y Previsión Social y su máximo jerarca -el Director del Trabajo- es funcionario de confianza exclusiva del Presidente, lo cual somete a la Dirección a los lineamientos políticos del gobierno de turno y definitivamente no es un órgano imparcial frente a los actores de las relaciones laborales porque, aunque se la define como un servicio "técnico", en la práctica asume un papel de defensa de los intereses de los trabajadores frente a los empleadores. Para sortear estas objeciones, alguna doctrina arguye que la intervención de la Inspección del Trabajo sería un requisito de procesabilidad "sin formar parte del proceso monitorio, ni constituir una etapa del mismo". PereIRA, R., op. cit. (n. 12), p. 46. y reitera la misma idea en pp. 59-60. Despejado el ripio, el "argumento" es del tipo hoc volo, sic iubeo, sit pro ratione voluntas, esto es, puro voluntarismo del autor, quien pretende borrar de un plumazo la letra de la ley. En efecto, fue el propio legislador quien reguló expresamente la comparecencia ante la Inspección del Trabajo dentro del párrafo 7 del Título I del Libro V CT, bajo el epígrafe Del procedimiento monitorio y ese mismo legislador estableció la relevancia que puede tener la comparecencia de las partes en la etapa administrativa (sic) en el examen de fondo que realizará el juez en la etapa judicial del procedimiento para decidir si se pronuncia de plano o abre el contencioso -artículo 500 inciso $1 \mathrm{CT}$-. No debe pasarse por alto tampoco el lenguaje típicamente procesal utilizado en las disposiciones relativas a la etapa administrativa del procedimiento: se habla reiteradamente de partes y se les ordena comparecer ante la Inspección del Trabajo con los instrumentos probatorios de que dispongan -artículo 497 inciso 4 CT-. Un requisito de procesabilidad es un presupuesto formal para dar curso a la acción, que agota su función in limine litis, pero que carece de relevancia para el pronunciamiento de fondo, como ocurre, por ejemplo, con la norma contenida en el art. 106 de la ley 19.968, que establece los casos en que, en los procedimientos de familia, es necesaria una mediación previa. En cambio, en el monitorio laboral la comparecencia de las partes a la etapa administrativa no es solo una condición formal para iniciar el procedimiento sino que además debe ser considerada por el juez para el pronunciamiento de fondo.
} 
Si el juez estima fundadas las pretensiones del demandante, las acogerá inmediatamente; en caso contrario las rechazará de plano; o, como tercera opción, en caso de no existir antecedentes suficientes para este pronunciamiento, el juez puede emitir una suerte de non liquet, debiendo en tal caso provocar oficiosamente el contradictorio, bajo la forma de una audiencia única de conciliación, contestación, prueba y sentencia a la que deberán ser citadas las partes. En cualquier caso, como paso previo a dictar sentencia inaudita altera parte, o a provocar el contradictorio, la ley obliga al juez a efectuar un examen de mérito sobre los fundamentos de la demanda, exclusivamente sobre la base de los antecedentes aportados por el actor ${ }^{21}$, el cual deberá considerar, además, la complejidad del asunto que se somete a su decisión, la comparecencia de las partes a la etapa administrativa y la existencia de pagos efectuados por el demandado -artículo 500 inciso primero CT-.

Si la sentencia fuere dictada inaudita altera parte, las partes solo podrán reclamar de esta resolución dentro del plazo de diez días hábiles contados desde su notificación, sin que proceda contra ella ningún otro recurso -artículo 500 inciso segundo CT-. Por lo que debe entenderse que la sentencia queda firme si no se presenta oportunamente este único recurso. En tal caso, si no se acredita el cumplimiento de la sentencia dentro del término de cinco días, el juez deberá iniciar la ejecución oficiosa de la misma conforme a las reglas generales -artículo 462 y ss. CT-.

Presentada la reclamación dentro de plazo, el juez citará a las partes a una audiencia única de conciliación, contestación y prueba -artículo 500 inciso quinto CT-. El juez deberá dictar sentencia al término de la audiencia. La ley lo faculta para omitir en su fallo la síntesis de los hechós y de las alegaciones de las partes y el análisis de toda la prueba rendida, los hechos que estime probados y el razonamiento que conduce a estą estimación -artículo 501 inciso final CT-22. Contra esta sentencia solo procede el recurso de nulidad, conforme a las reglas generales -artículo 477 y ss. CT-, pero contra la resolución que falle el recurso de nulidad no podrá interponerse el recurso de unificación de jurisprudencia artículo 502 CT-.

\section{LA SENTENCIA ANTICIPADA}

Las formas monitorias se inician mediante una petición verbal o escrita del acreedor que puede ser, según las distintas legislaciones, simple -procedimiento monitorio puro- o exigir un antecedente escrito -procedimiento monitorio documental-; como respuesta a esta petición, el juez libra, sin oír a la otra parte, un mandato, aviso, intimación o requerimiento de pago que se notifica al deudor y si este no reclama en un plazo determinado se configura

\footnotetext{
${ }^{21}$ De esta forma, se practica unilateralmente toda la prueba necesaria para lograr en el juez la convicción de la razón expuesta por el actor y se impide al demandado el control de la prueba de cargo y se elimina la posibilidad de presentar la de descargo. Alvarado, A., op. cit. (n. 5), p. 588.

22 Reduciendo a cero la posibilidad de control de racionalidad de la sentencia en lo que se refiere a las cuestiones de hecho. El Tribunal Constitucional evitó pronunciarse sobre la evidente inconstitucionalidad de la norma so pretexto de que la norma cuestionada "no ha tenido aplicación en el caso sublite". Todavía más sorprendente es la prevención de los ministros Fernández y Carmona que justifican esta aberración bajo el argumento que "la exigencia de fundamentación no implica que todas las sentencias deben tener un exhaustivo y completo análisis de los antecedentes". Sentencia de 12 de octubre de 2010, rol 1514-09.
} 
un título ejecutivo definitivo o provisional, dependiendo si el procedimiento monitorio está configurado en una o varias fases, respectivamente.

Es muy importante destacar que en las formas monitorias la intimación de pago no es todavia una sentencia condenatoria contra el deudor ${ }^{23}$. No puede serlo, porque hasta ese minuto no ha habido propiamente cognición. Esto es evidente en el proceso monitorio "puro" en que falta toda cognición de mérito al momento en que la orden de pago es emitida, pues, como nos recuerda Calamandrei, "el juez, antes de librarla, se limita a examinar si existen en concreto las condiciones formales para la emanación de la providencia exigida" 24 , vale decir, a ejercer el control sobre los presupuestos legales que permiten el uso de la vía monitoria. Pero incluso en el monitorio documental, el juez no emite un juicio de verosimilitud sobre la pretensión, sobre la base de una prueba documental, sino que simplemente verifica un requisito adicional de admisibilidad de la demanda. La fase de cognición se completa recién con el transcurso del término sin oposición del deudor. "En ese segundo momento, la orden de pago no se basa ya solamente, como en el momento en que ha sido librada, sobre la simple declaración unilateral del acreedor, sino que se basa, además y sobre todo, sobre la falta de contradicción por parte del deudor" ${ }^{25}$, que -como quedó dicho más arriba- se considera como confesión, allanamiento y/o reconocimiento tácito de la pretensión, lo cual viene a justificar, recién ahora, la declaración de certeza contenida en la sentencia monitoria.

En el procedimiento monitorio laboral, en cambio, la ley obliga al juez a efectuar un examen de mérito sobre los fundamentos de la demanda y, si considera que hay antecedentes suficientes, dicho juez dictará sentencia acogiendo o rechazando la demanda, esto es, resolviendo el fondo de la pretensión formulada por el actor, sin oír ni darle siquiera la oportunidad de ser oído al demandado. Es falso que esto sea "la genuina expresión de la técnica monitoria"26. En las formas monitorias auténticas la resolución que se dicta inaudita altera parte no es todavía sentencia puesto que la fase de cognición no está completa sino hasta que trascurra el término para que el demandado pueda oponerse habiendo este permanecido inactivo. $\mathrm{Si}$, en cambio, el demandado se opusiere al requerimiento de pago, esta resolución se desvanece y, conjuntamente con ella, se extingue también el procedimiento monitorio mismo. Esta muerte del monitorio es una consecuencia lógica de la oposición del demando porque no puede operar ya la presunción de confesión, allanamiento y/o reconocimiento tácito de la pretensión del actor que es la llave que cierra la fase de cognición en las formas monitorias europeas. En los monitorios europeos no existe contradicción ni proceso posterior de conocimiento ${ }^{27}$.

Én el monitorio chileno, las cosas suceden de un modo muy distinto puesto que, cuando el juez estima que hay antecedentes suficientes y falla de plano, la fase de cogni-

\footnotetext{
23 "Monitorio, no tiene otro sentido en italiano que: advertencia, apercibimiento o requerimiento que se dirige a una persona (en este caso el deudor para que pague)". MANASSERO, A. "Procedimiento monitorio, una alternativa a la celeridad. Una materia pendiente en las legislaciones de América Latina. Su dificultad de implementación", en DE LA FUENTE, P. (coord.). Estudios de Derecho Procesal Civil. Bases para un nuevo Código Procesal Civil, Librotecnia, Santiago de Chile, 2010, p. 256.

${ }^{24}$ Calamandrei, P. op. cit. (n. 9), p. 61.

${ }^{25}$ Calamandrei, P., op. cit. (n. 9), p. 62.

${ }^{26}$ Cfr. Pereira, R., op. cit. (n. 12), p. 58.

27 PEREZ, A., op. cit., (n. 6), p. 463.
} 
ción se agota en el examen de los antecedentes que ofrece el demandante y, así, la primera resolución que dicta el tribunal nace, en rigor, como sentencia definitiva, puesto que acoge o rechaza la pretensión y de este modo resuelve el litigio. Resulta evidente que en nuestro monitorio la pasividad del perdidoso no cumple ninguna función en relación con la cognición, no la integra, puesto que el litigio se decidió antes de iniciar siquiera el transcurso del término para la oposición ${ }^{28}$. Salta también a la vista que si esa oposición se materializa, la sentencia monitoria no desaparecerá, sino que simplemente quedará en suspenso su ejecución hasta tanto sea confurmada por el propio tribunal (jeventualmente por el mismo juez que la dictó!).

Como consecuencia de lo anterior, el procedimiento monitorio laboral no consigue sortear la objeción que plantea la regla constitucional -artículo 19 No 3 CPR-, según la cual "toda sentencia de un órgano que ejerza jurisdicción debe fundarse en un proceso previo legalmente tramitado". La regla constitucional transcripta exige que la sentencia haya sido precedida de una tramitación anterior a ella, en que el afectado haya sido oído en sus defensas y en sus pruebas ${ }^{29}$ o, cuando menos, en que el demandado haya tenido la posibilidad procedimental de oponerse, como sucede en las genuinas formas monitorias. Claramente nuestra Carta Fundamental veda al legislador y al juez la anticipación de la sentencia inaudita altera parte.

Entonces, cuando el artículo $500 \mathrm{CT}$ autoriza al juez a dictar la sentencia pronunciándose sobre el fondo de la demanda prematuramente, esto es, sin audiencia previa del demandado, no solo burla en forma directa el mandato de la Constitución, configurándose como una disposición legal abiertamente inconstitucional, sino que además infringe el sistema de garantías y derechos que las naciones civilizadas denominan debido proceso y que la propia Carta Fundamental recoge bajo la expresión procedimiento racional y justo. Específicamente la garantía a la defensa procesal, traducida al menos como posibilidad de responder a la demanda, reconocida en todos los ordenamientos como requisito esencial para la valida constitución de un proceso ${ }^{30}$.

Se arguye por los defensores del monitorio laboral que "la decisión de acoger la demanda sin haber escuchado previamente al demandado es provisoria. El demandado, luego de notificársele la demanda y la decisión del juez, todavía tiene derecho a controvertir lo dicho por el demandante, exigiendo un juicio oral, público y contradictorio" 31 . De este modo los principios de contradicción y bilateralidad y, por ende, el debido proceso quedarían a salvo en el monitorio laboral por la posibilidad de recurrir contra la sentencia. Esto no pasa de ser una falacia. Y es que, "procesalmente hablando, no es lo mismo contestar una demanda que expresar agravios contra una sentencia [porque] la defensa ha de tener una oportu-

\footnotetext{
${ }^{28}$ La sentencia así dictada se acerca peligrosamente a la "medida autosatisfactiva" en cuanto esta surge cuando se confiere al juez "la potestad de decidir muy tempramente, generalmente in limine, sobre el fondo mismo de lo que se le pide sin intervención alguna del afectado por esa resolución". (Calvinho, G.: "Medidas cautelares, turelas anticipadas y sencencias autosatisfactivas ante el debido proceso", en Vox Iuris, Revista del Ilustre Colegio de Abogados de Puno, vol. 9, diciembre, 2009, Puno-Perú, p. 72).

29 EVANS, E. Los derechos constitucionales -3a edición-. Santiago: Editorial Jurídica de Chile, 2004, tomo II, p. 143.

30 CAROCCA, A. Garantía constitucional de la defensa procesal. Barcelona: Bosch, 1998, pp. 17-18.

${ }^{31}$ Felipe Marín, citado en: PEREIRA, R., op. cit. (n. 12), p. 13.
} 
nidad que la haga previa a la primera decisión, no bastando que esa oportunidad se brinde recién después que quien juzga en primer término ya se ha pronunciado" 32 . En efecto, el otorgamiento de una vía posterior que pueda llevar a la "reversión" de los efectos producidos implicaría una restitución del derecho de defensa porque la realidad es que primero se viola el derecho de defensa y luego se lo restituye, pero menguado" 33 . Y, entonces:

“...que no se diga que la 'bilateralidad' o la 'audiencia' se logra porque [...] el demandado puede recurrir de lo decidido $y$, con esa actividad de 'impugnación', se estaría salvando la 'contradicción proçesal'. Sencillamente ese no es el ideario Constitucional de la audiencia debida [...] en procesos de conocimiento en donde no hay derechos ya declarados, sino meras expectativas de esos derechos [...] la Constitución y los Códigos Procesales que hacen operativa la garantía del debido proceso aseguran (o mejor dicho deberían siempre asegurar) la conexión inicial y continua de las instancias entre tres sujetos (en definitiva el proceso) y no que entre las afirmaciones 'fuertemente verosímiles' de pretendiente y un juez se encarguen (uno por pedir y el otro por otorgar) de generar un simple procedimiento y que, sin embargo, y esto es lo grave, tenga la misma virtualidad para privar de un 'bien de la vida' a una persona que un proceso (en sentido que es un trámite de a 'dos'), pero de él deriva una sentencia que afecta procesalmente al demandado al ser alcanzado por sus efectos cuando no estuvo precedida de un debate 'en serio' entre las partes..."34.

$\mathrm{Y}$ es que, como observa agudamente Alvarado, "el oponente del demandado es el actor, no el juez; si, en cambio, la audiencia viene después de la sentencia, lo que se rebate son los términos de una decisión judicial, no los dichos del actor" 35 .

Si el sistema recursivo fuera suficiente garantía de la bilateralidad de la audiencia y en último término del debido proceso -como arguyen falazmente los defensores del monitorio laboral- nos preguntamos ¿por qué, entonces, no permitir en todos los procedimientos la dictación de sentencia definitiva inaudita altera parte conservando la posibilidad de recurrirla? ¿Por qué no deshacerse de una buena vez de la anticuada idea de la bilateralidad de la audiencia y del contradictorio como garantías necesarias en todas las etapas procesales y trasladarlas a una fase posterior y eventual, al cuarto de atrás del proceso, como si fueran parientes locos o de algún modo inconvenientes, que solo pudieran aparecer por la casa después que el juez terminó su tarea y abandonó la sala? De ese modo se ganaría mucho en celeridad, aunque antes, claro, habría que reformar la Constitución Política. Nos parece que no es necesario decir más para demostrar que el argumento conduce al absurdo.

\footnotetext{
32 Bidart Campos, citado en: BORDENAVE, L. La medida autosatisfactiva como solución inconstitucional para un problema de la justicia moderna. Rosario -Argentina-: Editorial Juris, 2009, p. 90.

33 BORDENAVE, L., op. cit. (n. 32), p. 91.

${ }^{34}$ BENABENTOS, O. Teoría general unitaria del Derecho procesal. Rosario -Argentina-: Editorial Juris, 2001, pp. 373-374.

${ }^{35}$ Alvarado, A., op. cit. (n. 5), p. 594.
} 


\section{PALABRAS FINALES: HACIA LA JURISDICCIÓN SIN PROCESO}

El juez es un ciudadano al que la comunidad organizada le atribuye el poder de decidir, de resolver el conflicto intersubjetivo. Este poder de decidir sobre la persona y los bienes de los ciudadanos, según lo manda la ley, se llama jurisdicción. No es pequeńo este poder. Por tanto su ejercicio debe ser encauzado dentro de ciertos márgenes, para evitar que, cual torrente incontrolado, se desborde y, fuera de control, se torne arbitrario y opresor ${ }^{36}$.

Es por eso que el ejercicio de la jurisdicción desde tiempos inmemoriales se enmarca dentro de una especial ritualidad o forma, mediante unos concretos actos que se despliegan en el tiempo y que obedecen a un orden lógico y necesario: primero, la afirmación del pretendiente; en segundo lugar, la posibilidad de oposición del resistente; en tercer lugar, la confirmación, donde pretendiente y resistente aportan los medios que consideran idóneos para formar la convicción del juez en favor de sus respectivas narraciones; y en cuarto lugar, la conclusión o cierre del debate durante el cual cada parte evalúa el material probatorio encuadrando los hechos acreditados en la norma jurídica que rige el caso sometido a juzgamiento. Sin la totalidad de los actos que componen la serie no existe proceso, ya que tal serie es la que hace que un proceso sea un proceso y no otra $\operatorname{cosa}^{37}$.

Cuando por mor de celeridad la ley autoriza al juez para anticipar la pretensión del actor inaudita altera parte, hay un olvido brutal del debido proceso. Pues, como dice Alvarado:

"en un proceso de conocimiento el juez no sabe (¡no puede saberlo!) si le asiste derecho al actor que lo invoca. Si con solo escuchar al pretendiente le concede la razón, ese juez solo por azar habrá acertado en la solución del litigio [...] la versión que brinda el actor, la prueba que él puede arrimar, en definitiva, el "tañido de la campana que él mismo bate", no es más que eso: la presentación de los hechos desde su óptica, desde su particularidad, desde su puro subjetivismo [...] la "fuerte verosimilitud", la "probabilidad cierta", la "irreparabilidad del perjuicio" deben necesariamente contrastarse con la versión, con la certeza y con el propio perjuicio irreparable de quien en los hechos viene aponiéndose a la pretensión de actor ${ }^{38}$.

Estamos retrocediendo a lo más oșcuro de la historia jurídica so pretexto de brindar una supuesta justicia rápida y eficiente ${ }^{39}$.

Presenciamos el ejercicio de la jurisdicción desnuda, marchamos hacia la jurisdicción sin proceso.

\footnotetext{
${ }^{36}$ Palavecino, C. "Sistemas procesales e ideología. Reflexiones a propósito de la reforma procesal laboral chilena", en: Revista Dogmática Procesal Latinoamericana. Temas de Derecho procesal $N^{\circ} 4$. Perú: Instituto Sudamericano de Dogmática Procesal, Capítulo Perú, octubre 2010, p. 17.

${ }^{37}$ AlVARADO, A., op. cit. (n. 5), p. 41-43.

${ }^{38}$ Alvarado, A., op. cit. (n. 5), p. 593.

${ }^{39}$ Alvarado, A., op. cit. (n. 5), p. 594.
} 


\section{BIBLIOGRAFÍA}

Albiol, I; Alfonso C.; Blasco, A.; y Goerlich, J. Ma . Derecho Procesal Laboral-3a edición-. Valencia: Tirant lo Blanch, 2000.

Alvarado, A. Sistema Procesal. Garantía de la libertad. Dos tomos. Buenos Aires: Rubinzal-Culzoni, 2009.

ÁlvareZ, P. Tutela Anticipada. Córdoba -Argentina-: Alveroni Ediciones, 2008.

BENABENTOS, O. Teoría general unitaria del Derecho procesal. Rosario-Argentina-: Editorial Juris, 2001.

BERIzONCE, R. Tutelas procesales diferenciadas, Buenos Aires: Rubinzal-Culzoni, 2009.

BORDENAVE, L. La medida autosatisfactiva como solución inconstitucional para un problema de la justicia moderna. Rosario-Argentina-: Editorial Juris, 2009.

CALAMANDREI, P. El procedimiento monitorio. Buenos Aires: Ediciones Jurídicas Europa-América (EJEA), 1953.

CALVINHO, G. "Medidas cautelares, tutelas anticipadas y sentencias autosatisfactivas ante el debido proceso", eni: Vox Iuris, Revista del Ilustre Colegio de Abogados de Puno, vol. 9, diciembre, 2009, Puno-Perú, pp. 69-73.

CAROCCA, A. Garantía constitucional de la defensa procesal. Barcelona: Bosch, $1998^{\circ}$.

CEDEÑO, M. "El proceso monitorio en el ordenamiento español. Un cauce para la eficaz protección del crédito", en: DE la OlIVA, A. y PALOMO, D. (Coord.). Proceso civil. Hacia una nueva justicia civil. Santiago: Editorial Jurídica de Chile, 2007.

EVANS, E. Los derechos constitucionales $-3^{a}$ edición-. Santiago: Editorial Jurídica de Chile, 2004.

MANASSERO, A. "Procedimiento monitorio, una alternativa a la celeridad procesal. Una materia pendiente en las legislaciones de América Latina. Su dificultad de implementación", en DE LA FUENTE, P. (coord.): Estudios de Derecho Procesal Civil. Bases para un nuevo Código Procesal Civil, Librotecnia, Santiago de Chile, 2010, pp. 255-282.

PALAVECINO, C. "Sistemas procesales e ideología. Reflexiones a propósito de la reforma procesal laboral chilena", en: Revista Dogmática Procesal Latinoamericana. Temas de Derecho procesal No 4. Perú: Instituto Sudamericano de Dogmática Procesal, Capítulo Perú, octubre 2010.

Pereira, R. El procedimiento monitorio laboral. Santiago: Abeledo Perrot LegalPublishing, 2010.

PÉREZ, A. "En torno al proceso monitorio desde el derecho procesal comparado europeo y hacia un monitorio comunitario. Caracterización y elementos", en: DE LA Oliva, A. / PALOMO, D. (Coord.). Proceso civil. Hacia una nueva justicia civil. Santiago: Editorial Jurídica de Chile, 2007. 